\title{
Open transcatheter valve implantation for mitral annular calcification: One-year outcomes
}

\author{
Umar Imran Hamid, MD, ${ }^{\mathrm{a}}$ Anne Gregg, RGN, ${ }^{\mathrm{a}}$ Peter Ball, FRCR, ${ }^{\mathrm{b}}$ Colum Owens, MD, \\ Ganesh Manoharan, FRCP, ${ }^{\mathrm{c}}$ Mark S. Spence, FRCP, ${ }^{\mathrm{c}}$ and Reuben Jeganathan, FRCS $^{\mathrm{a}}$
}

\section{ABSTRACT}

Background: Transcatheter mitral valve implantation (TMVI) for native mitral valve pathology with severe mitral annular calcification has emerged as an alternative treatment option to conventional mitral valve surgery. The objective of this study was to evaluate patients who were referred for TMVI with severe mitral annular calcification and their procedural outcomes.

Methods: Retrospective analysis of patients from 2017 to 2020 referred for TMVI was carried out. Demographic characteristic details; surgical strategy; perioperative complications; and hospital stay, including 30-day and 1-year mortality, were analyzed.

Results: Eleven patients were referred for consideration of TMVI. The 8 patients who underwent TMVI had a median age of 74 years (range, 57-80 years), the median Society of Thoracic Surgeons score was 4.6 (range, 2.4-10.9), and European System for Cardiac Operative Risk Evaluation II score was 5.2\% (2\%-10.1\%). The median cardiopulmonary bypass time and crossclamp times were 170 minutes (range, 150-248 minutes) and 152 minutes (range, 118-214 minutes), respectively. The median hospital stay was 29 days (range, $2-40$ days). Thirty-day in hospital mortality was $12 \%$, whereas 1 -year mortality was $25 \%$. There was symptomatic improvement with downgrade of New York Heart Association functional class from III or IV to I or II. The 3 patients who were turned down had a median age of 73 years, median Society of Thoracic Surgeons score was 13.4, and median European System for Cardiac Operative Risk Evaluation II score was $5.72 \%$. They were alive at 12 months follow-up from the date of surgical assessment; however, all with New York Heart Association functional class III or IV symptoms.

Conclusions: We describe a series demonstrating the technical consideration and capability of transatrial TMVI to treat mitral annular calcification and native mitral valve disease. Our results are favorable when compared with TMVI global registry data for transseptal or transapical approach. (JTCVS Techniques 2021;10:254-61)

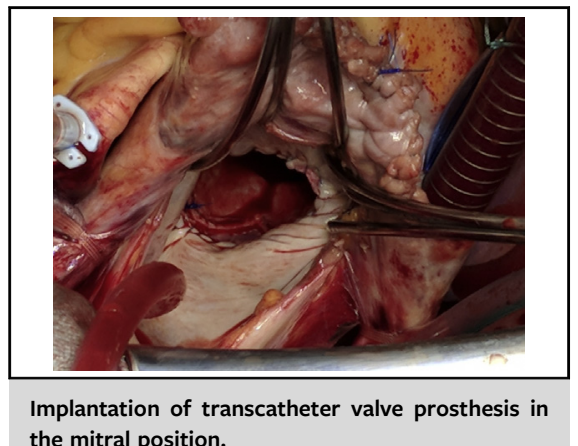
the mitral position.

\section{CENTRAL MESSAGE \\ Transatrial transcatheter mitral \\ valve implantation in mitral \\ annular calcification has accept- \\ able outcomes. The postopera- \\ tive course of patients is \\ reflective of their comorbidities.}

\section{PERSPECTIVE}

Conventional MV replacement is associated with high mortality in the setting of mitral annular calcification. Transatrial transcatheter MV implantation in native MV pathology with mitral annular calcification has emerged as an alternative treatment option to conventional MV surgery. The objective of this study was to evaluate outcomes after transatrial transcatheter MV implantation.

See Commentaries on pages 262 and 264 .

$\square$ Video clip is available online.

From the Departments of acCardiothoracic Surgery, ${ }^{\mathrm{b}}$ Radiology, and ${ }^{\mathrm{c}}$ Cardiology, Royal Victoria Hospital, Belfast, United Kingdom.

Received for publication March 30, 2021; accepted for publication Aug 3, 2021; available ahead of print Aug 10, 2021.

Address for reprints: Umar Imran Hamid, MD, Department of Cardiothoracic Surgery, Royal Victoria Hospital, Grosvenor Road, Belfast, BT12 6BA, United Kingdom (E-mail: umar.hamid@belfasttrust.hscni.net).

2666-2507

Copyright $(92021$ The Author(s). Published by Elsevier Inc. on behalf of The American Association for Thoracic Surgery. This is an open access article under the CC BY-NC-ND license (http://creativecommons.org/licenses/by-nc-nd/4.0/).

https://doi.org/10.1016/j.xjtc.2021.08.004
Mitral annular calcification (MAC) is increasingly encountered in the ageing population with coexisting mitral valve disease. ${ }^{1}$ Mitral valve replacement in patients with MAC have a high perioperative morbidity and mortality. ${ }^{2}$ Although there are multiple strategies to address the calcified annulus, each has its own challenges. Conventional mitral valve replacement has been the standard practice but poses the potential risk of atrioventricular disruption and paravalvular leaks (PVLs). ${ }^{3,4}$ A novel approach during 


\section{Abbreviations and Acronyms}

CT = computed tomography

Euroscore II = European System for Cardiac

Operative Risk Evaluation II

$\begin{array}{ll}\text { LVOT } & =\text { left ventricular outflow tract } \\ \text { MAC } & =\text { mitral annular calcification } \\ \text { NYHA } & =\text { New York Heart Association } \\ \text { PVL } & =\text { paravalvular leak } \\ \text { STS } & = \\ \text { TMVI } & =\text { transcaty of Thoracic Surgeons } \\ & \text { implantation mitral valve }\end{array}$

the past few years has been to implant a transcatheter valve in the mitral valve position in the presence of severe MAC. ${ }^{5}$ Data from the Transcatheter Mitral Valve Implantation (TMVI) in MAC Global Registry and more recently, the Mitral Implantation of Transcatheter Valves study, have reiterated that the "techniques still require further refinement." 6

The objective of this study was to evaluate our patients who were referred for TMVI with severe MAC to analyze the technical challenges encountered during surgery; strategies to alleviate them; and hospital outcomes, including 30 day and 1-year mortality (Figure 1).

\section{METHODS}

Retrospective analysis of patients from 2017 to 2020 referred for TMVI was carried out. Demographic characteristic details; surgical strategy; perioperative complications; and hospital stay, including 30-day and 1-year mortality, were analyzed. The equivalent local ethics committee at the Belfast Health and Social Care Trust approved the study protocol and contents for publication (approval No. 6439 with approval date June 28, 2021). The consent of the patients was waived due to lack of patient identifiers in the script.

\section{Technique for Open TMVI}

On institution of cardiopulmonary bypass with bicaval cannulation, the heart was arrested using antegrade and/or retrograde blood/crystalloid cardioplegia (St Thomas or Custodial solution). After left atriotomy via the Sondergaard's groove, the mitral valve was inspected. The anterior mitral leaflet was excised to prevent left ventricular outflow tract (LVOT) obstruction (Figure 2). The annulus was then sized with either a 25- and/or 29-mm Edwards balloon (Edwards Lifesciences, Irvine, Calif). Any potential sites for PVL were obliterated using polytetrafluoroethylene felt in the initial first few cases. A Sapien 3 valve (Edwards Lifesciences) of corresponding size was then implanted under direct visualization with careful adjustment to ensure the skirt of the valve was along the annular or supra-annular plane. We moved from the 3-part fixation in the first few cases to partial and then full continuous suturing of the atrial tissue to the skirt of the Sapien 3 valve, which obliterates any potential PVL (Figure 3).

In patients where the annulus was too large for a $29-\mathrm{mm}$ balloon, a size-30 Physio II ring (Edwards Life Sciences) was implanted onto the annulus using both the leaflet and the atrial wall tissue to anchor in areas of calcification (2.0 Ethibond sutures), following which the Sapien 3 valve was then implanted in a valve-in-ring fashion. Figure 4 highlights a fluoroscopic image of a dilated calcified annulus with a size-29 Sapien 3

\section{Single institutional experience of trans-catheter mitral valve implantation for mitral valve pathology with} severe mitral annular calcification.

\section{Methods: 2017 - 2020, 8 patients underwent TMVI.}
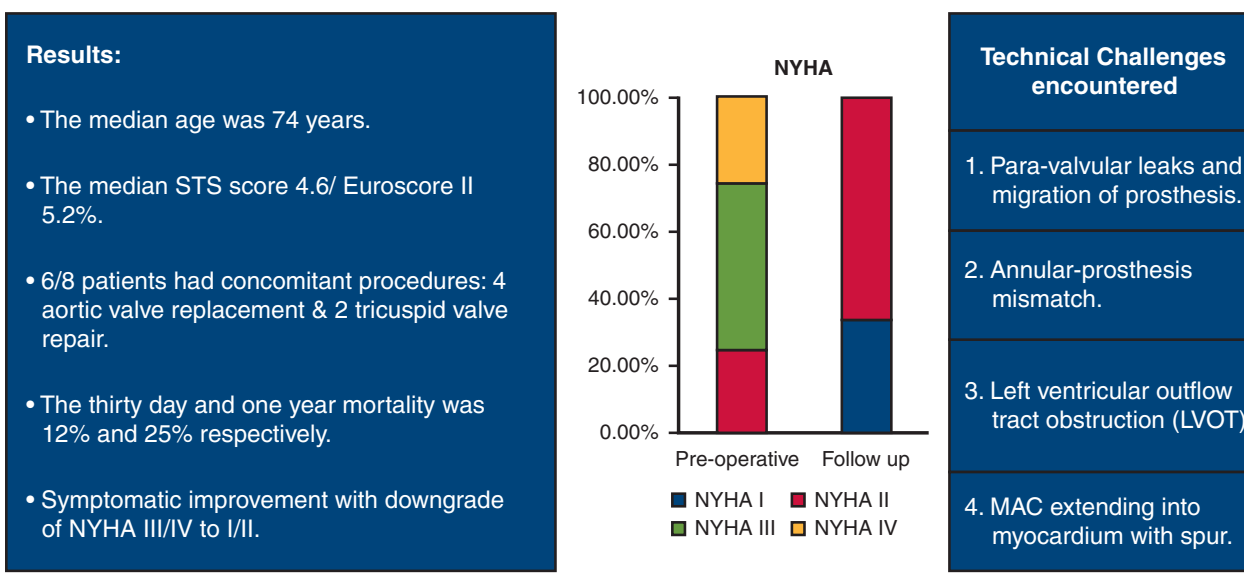

Solution Identified

Suturing the atrial tissue onto the skirt of the transcatheter valve prosthesis.

Implanting a complete annuloplasty ring for valve in ring implantation.

Resolved by excision of anterior mitral leaflet and orientating the prosthesis away from the LVOT.

CT planning essential with debridement of calcium that can potentially migrate.

Implications: Trans-atrial TMVI in MAC for native mitral valve pathology can deal with the technical challenges with improved procedural outcomes. Patient selection should be carried out with heart team discussion to identify those who are likely to benefit prognostically and symptomatically.

FIGURE 1. Outcomes after open transcatheter implantation of Sapien 3 (Edwards Life Sciences, Irvine, Calif) prosthesis in the mitral position in the setting of mitral annular calcification. TMVI, Transcatheter mitral valve implantation; NYHA, New York Heart Association; STS, Society of Thoracic Surgeons; $M A C$, mitral annular calcification; $C T$, computed tomography. 


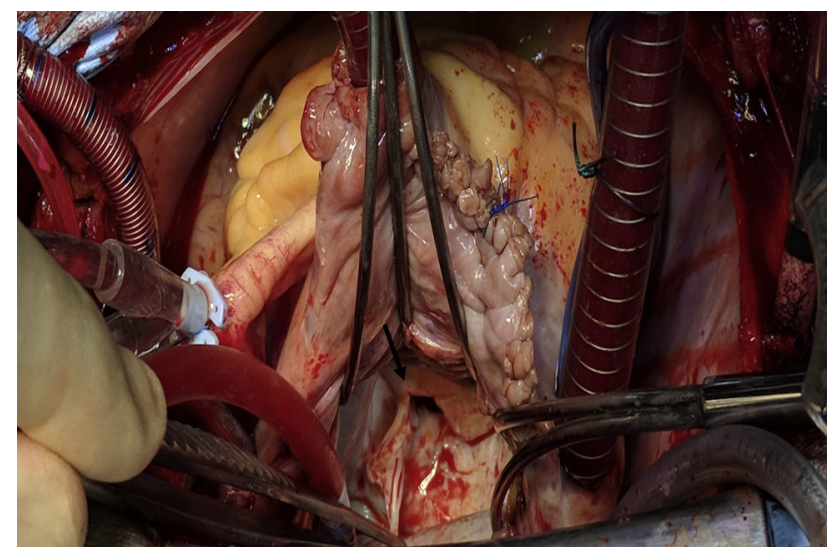

FIGURE 2. Access to the left atrium through the Sondergaard's groove with mitral retractors in situ. Excision of anterior mitral leaflet (black arrow) to prevent left ventricular outflow tract obstruction.

valve in a size-30 Physio II ring. Following closure of the atriotomy and de-airing of the LV via the aortic root, the patient was weaned off cardiopulmonary bypass. Transesophageal echocardiography was used to assess PVLs, gradient across the aortic valve, LVOT, mitral valve, and any evidence of migration.

Any moderate or severe PVL if identified after implantation with transesophageal echocardiography can be corrected by reinforcing the area with polytetrafluoroethylene pledgets. In patient 8 , due to poor visualization of the mitral valve via the left atriotomy, an open transeptal approach was undertaken with video-assisted guidance. A polytetrafluoroethylene strip was sutured onto the skirt of the Sapien 3 prosthesis to obliterate any potential PVL (Figure 5).

\section{RESULTS}

Eleven patients were referred for consideration of TMVI. Eight patients who underwent TMVI had a median age of 74 years (range, $57-80$ years) (7 women ad 1 man). Six

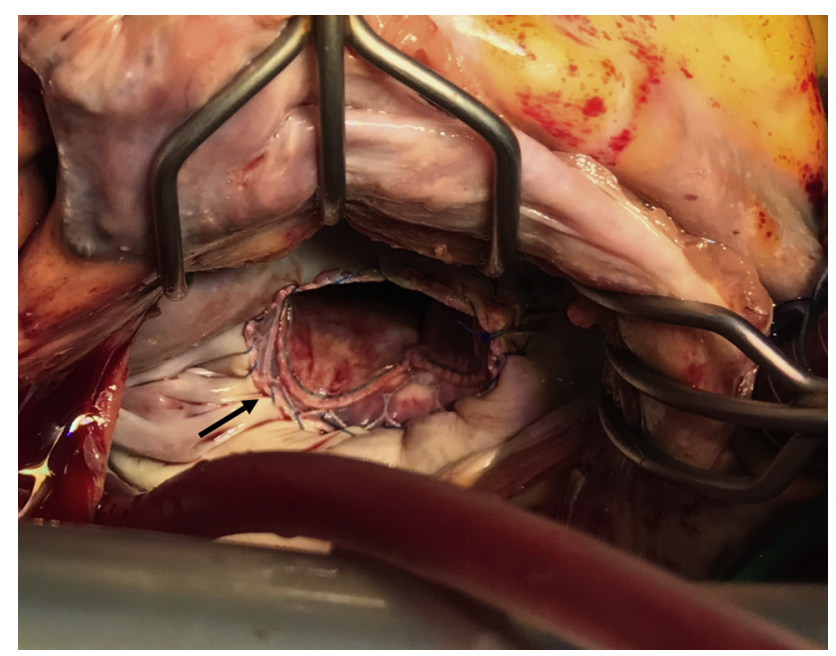

FIGURE 3. A running 4-0 Prolene (black arrow) to suture atrial tissue onto the skirt of the transcatheter mitral valve, Sapien 3 (Edwards Life Sciences, Irvine, Calif) prosthesis to prevent paravalvular leaks and valve migration.

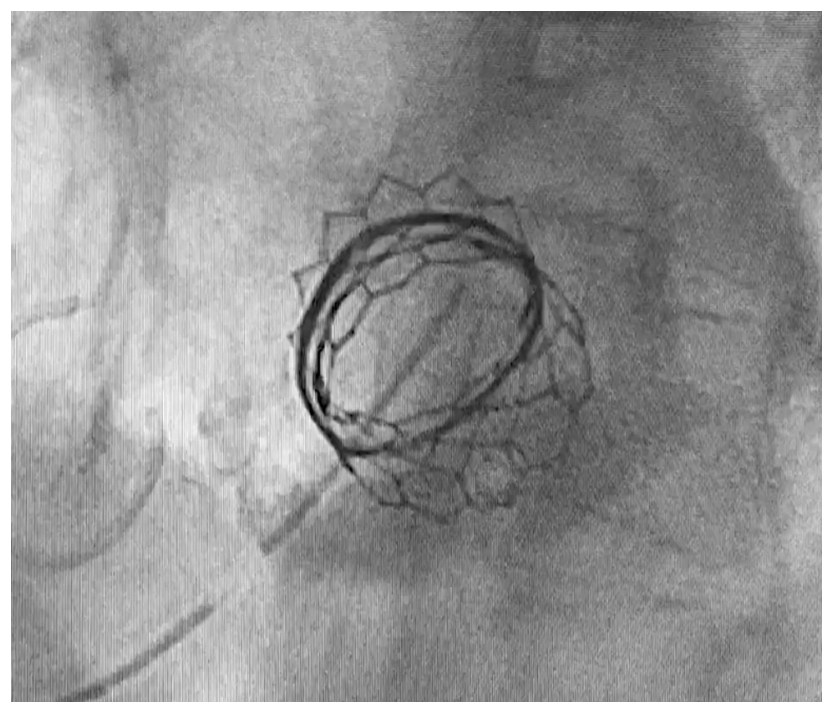

FIGURE 4. Fluoroscopy image following transatrial implantation of transcatheter mitral valve (Size 29 Sapien 3; Edwards Lifesciences, Irvine, Calif) in ring (Size 30 Physio II; Edwards Lifesciences) for a dilated calcified mitral annulus.

patients had preserved LV function but with diastolic dysfunction. Two patients had stage 3 kidney disease. The median Society of Thoracic Surgeons (STS) score was 4.6 (range, 2.4-10.9), and median European System for Cardiac Operative Risk Evaluation II (Euroscore II) score was 5.2\% (range, $2 \%-10.1 \%$ ). The median pulmonary systolic pressure was $48 \mathrm{~mm} \mathrm{Hg}$ (range, 25-105 mm Hg) (Table 1). Six patients underwent preoperative planning computed tomography (CT), which showed a $>270^{\circ}$ calcium distribution (Table 2). Six patients had concomitant valve procedures, for which 4 had aortic valve replacement and 2 had tricuspid valve repair as highlighted in Table 3. The median cardiopulmonary bypass time and crossclamp time were 170 minutes (range, 150-248 minutes) and 152 minutes (range, 118-214 minutes), respectively. Two patients required temporary postoperative renal replacement therapy, whereas 1 patient had nondebilitating stroke that resolved at 6 weeks' follow-up. Two patients had trivial and 1 patient had mild PVL. The median hospital stay was 29 days (range, 2-40 days) (Table 4). Thirty-day in hospital mortality was $12 \%$ (1 patient) and 1-year mortality was $25 \%$ ( 2 patients) (Table 5). Patient 3 in this case series had suspected LVOT obstruction following the procedure; however, due to poor echocardiographic views intra- and postoperatively, this could not be established. Patient 7 in this case series had an LV perforation that we believe was caused by calcium migrating beneath the posterior annulus (P3 region) secondary to the radial compression from the frame of the valve. This was managed by applying a hemosealant and packing with a successful outcome. There was symptomatic improvement of these patients 

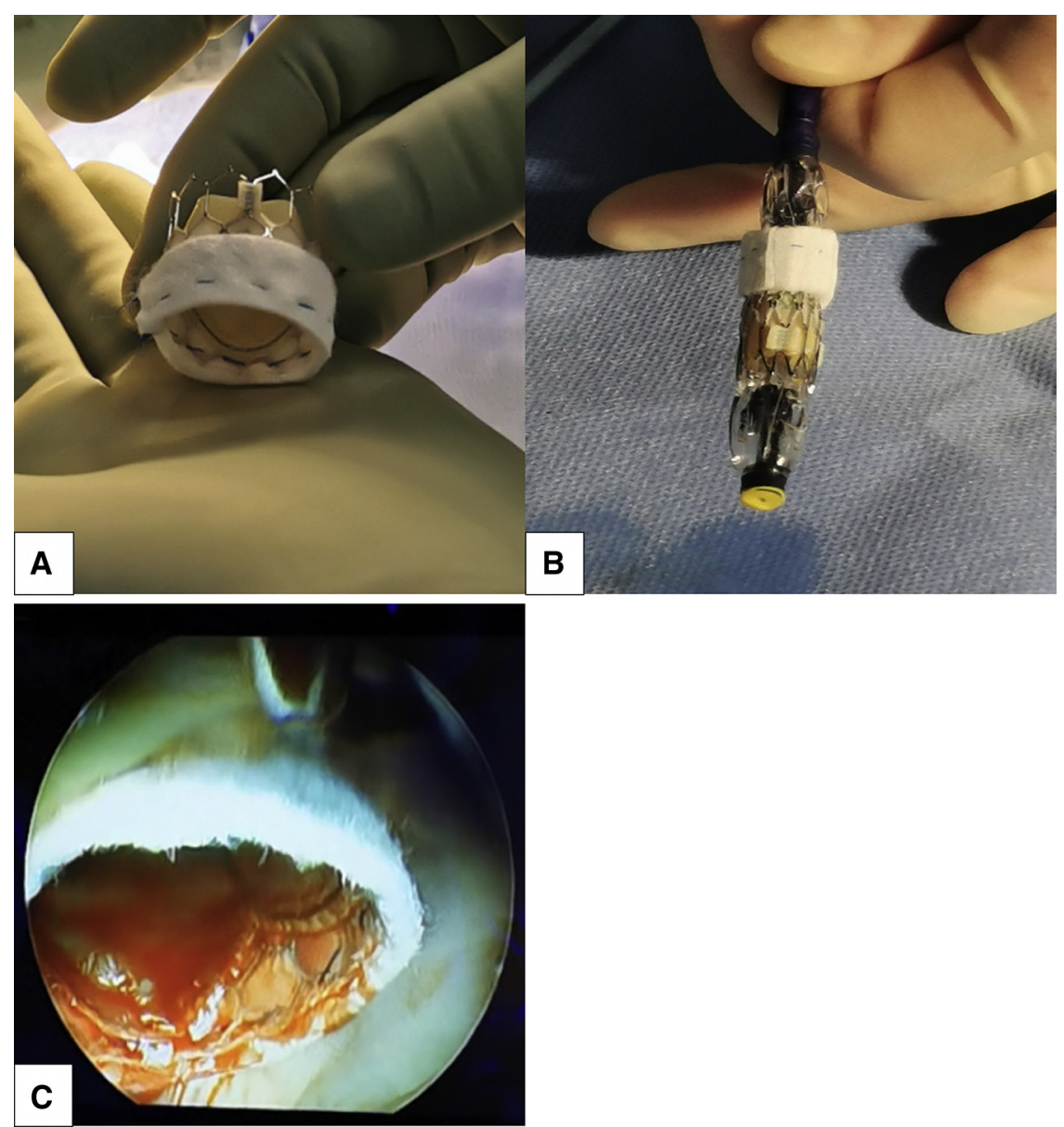

FIGURE 5. Securing a polytetrafluoroethylene strip onto the skirt of the transcatheter valve using a 4-0 prolene suture (Sapien 3; Edwards Lifesciences, Irvine, Calif) to mitigate against potential paravalvular leaks following implantation. A, Uncrimped valve. B, Crimped valve. C, Implanted transcatheter mitral valve.

with downgrade of New York Heart Association (NYHA) functional class from III or IV to I or II as detailed in Table 5.
The 3 patients who were turned down had a median age of 73 years, median STS score of 13.4, and median Euroscore II score of $5.72 \%$. They were alive at 12 months' follow-up

TABLE 1. Preoperative characteristics of patients undergoing transcatheter mitral valve implantation in mitral annular calcification

\begin{tabular}{|c|c|c|c|c|c|c|c|c|c|}
\hline Patient & Age (y) & Sex & $\begin{array}{c}\text { Preoperative } \\
\text { eGFR }\end{array}$ & STS score & ES II \% & LV function & $\begin{array}{c}\text { RV } \\
\text { function }\end{array}$ & $\begin{array}{c}\text { PA pressure } \\
(\mathbf{m m ~ H g})\end{array}$ & $\begin{array}{c}\text { NYHA } \\
\text { functional class }\end{array}$ \\
\hline 1 & 76 & $\mathrm{~F}$ & 60 & 10.9 & 4.9 & Mild impairment & $\begin{array}{l}\text { Mild to moderate } \\
\text { impairment }\end{array}$ & 61 & IV \\
\hline 2 & 68 & F & 60 & 2.44 & 3.2 & Normal & Normal & 50 & IV \\
\hline 3 & 76 & $\mathrm{~F}$ & 60 & 6 & 5.7 & Mild impairment & Mild impairment & 25 & III \\
\hline 4 & 78 & F & 40 & 3.78 & 10.1 & Normal & Normal & 105 & III \\
\hline 5 & 57 & $\mathrm{~F}$ & 45 & 2.4 & 2.7 & Normal & Normal & 53 & II \\
\hline 6 & 80 & F & 33 & 4.7 & 5.5 & Normal & Normal & 37 & III \\
\hline 7 & 67 & $\mathrm{~F}$ & 60 & 8.3 & 2 & Normal & Normal & 29 & II \\
\hline 8 & 73 & M & 60 & 4.57 & 9.9 & Normal & Normal & 30 & III \\
\hline
\end{tabular}

eGFR, Estimated glomerular filtration rate; STS, Society of Thoracic Surgeons; $E S$ II, European System for Cardiac Operative Risk Evaluation II, $L V$, left ventricle, $R V$, right ventricle, $P A$, pulmonary artery; NYHA, New York Heart Association. 
TABLE 2. Preoperative annular measurements and calcium distribution obtained from computed tomography images

\begin{tabular}{|c|c|c|c|c|c|c|c|c|}
\hline $\begin{array}{l}\text { Patient } \\
\text { No. }\end{array}$ & $\begin{array}{l}\text { MV maximum } \\
\text { diameter }(\mathbf{m m})\end{array}$ & $\begin{array}{c}\text { MV minimum } \\
\text { diameter }(\mathbf{m m})\end{array}$ & $\begin{array}{c}\text { Calcium } \\
\text { thickness } \\
(\mathbf{m m})\end{array}$ & $\begin{array}{c}\text { Calcium } \\
\text { distribution } \\
\left({ }^{\circ}\right)\end{array}$ & $\begin{array}{c}\text { Anterolateral } \\
\text { trigone } \\
\text { calcification }\end{array}$ & $\begin{array}{c}\text { Posteromedial } \\
\text { trigone } \\
\text { calcification }\end{array}$ & $\begin{array}{c}\text { Anterior mitral } \\
\text { leaflet } \\
\text { calcification }\end{array}$ & $\begin{array}{c}\text { Posterior mitral } \\
\text { leaflet } \\
\text { calcification }\end{array}$ \\
\hline 1 & 37.4 & 18.7 & $>5-<10$ & $>270$ & $Y$ & $Y$ & $\mathrm{Y}$ & $\mathrm{Y}$ \\
\hline 2 & 51.7 & 28.5 & $>10$ & $>270$ & Y & Y & $\mathrm{N}$ & $\mathrm{N}$ \\
\hline 3 & 36 & 21 & $>5-<10$ & $>270$ & $\mathrm{Y}$ & Y & $\mathrm{Y}$ & $\mathrm{N}$ \\
\hline 4 & 44.4 & 28.9 & $>10$ & $>270$ & $\mathrm{~N}$ & Y & $\mathrm{N}$ & $\mathrm{N}$ \\
\hline 5 & -* & & & & & & & \\
\hline 6 & -* & & & & & & & \\
\hline 7 & 35 & 20 & $>5-<10$ & $>270$ & $\mathrm{Y}$ & $\mathrm{Y}$ & $\mathrm{Y}$ & $\mathrm{N}$ \\
\hline 8 & 42 & 23 & $>10$ & $>270$ & Y & Y & $\mathrm{Y}$ & Y \\
\hline
\end{tabular}

$M V$, Mitral valve; $Y$, yes; $N$, no. *Preoperative computed tomography not done.

from the date of surgical assessment; however, all with NYHA functional class III or IV symptoms.

\section{DISCUSSION}

MAC is a degenerative process seen in $10 \%$ of the elderly population. ${ }^{1}$ This is a chronic course resulting from calcification of the fibrous mitral valve annulus. There are multiple risk factors for MAC, including advanced age, female sex, renal impairment, abnormal calcium/phosphate metabolism, and radiation exposure. ${ }^{7}$ The progression of the calcification over time results in mitral regurgitation and or mitral stenosis. Echocardiography and/or angiography provide a qualitative assessment of MAC, including its focal or circumferential distribution. However, cardiacgated CT is a superior imaging modality in assessing the location, extent of MAC, mitral valve sizing, and informing the risk of LVOT obstruction with the view to guide treatment strategy (Figure 6). Conventional mitral valve replacement in the presence of MAC can be carried out with annular debridement and reconstruction, but there is a substantial risk of atrioventricular rupture and PVLs. Other techniques include deep suture placement but with added risk of circumflex injury; intra-atrial prosthesis placement, which is associated with atrial dissection and bleeding ${ }^{1}$; and conduits from left atrium to the LV to bypass the calcified mitral annulus has also been used to address the mitral pathology. ${ }^{8}$

TMVI for native mitral valve pathology with severe MAC has emerged as an alternative treatment option. The TMVI in MAC Global Registry set up in 2013 included

TABLE 3. Intraoperative characteristics of patients undergoing transcatheter mitral valve implantation (TMVI) in mitral annular calcification (MAC)

\begin{tabular}{llcccc}
\hline $\begin{array}{c}\text { Patient } \\
\text { No. }\end{array}$ & Procedure & $\begin{array}{c}\text { CPB time } \\
(\mathbf{m i n})\end{array}$ & $\begin{array}{c}\text { Crossclamp } \\
\text { time }(\mathbf{m i n})\end{array}$ & $\begin{array}{c}\text { Technical challenges } \\
\text { encountered }\end{array}$ & Solution identified \\
\hline 1 & TMVI & 150 & 118 & Paravalvular leak & $\begin{array}{c}\text { Suturing the atrial tissue onto the skirt of the } \\
\text { transcatheter valve prosthesis }\end{array}$ \\
\hline 2 & TMVI + TVr & 168 & 151 & $\begin{array}{c}\text { Annular-prosthesis } \\
\text { mismatch }\end{array}$ & $\begin{array}{c}\text { Implanting a complete annuloplasty ring for valve-in- } \\
\text { ring implantation }\end{array}$ \\
\hline 3 & TMVI + AVR & 196 & 158 & Suspected LVOT & None \\
\hline 5 & TMVI + TVr & 138 & 119 & LVOT & $\begin{array}{c}\text { Resolved by excision of anterior mitral leaflet and } \\
\text { orientating the prosthesis away from the LVOT with a } \\
\text { higher atrial implant }\end{array}$ \\
\hline 6 & TMVI + AVR & 172 & 154 & & Annular-prosthesis \\
mismatch & Implanting a complete annuloplasty ring for valve-in- \\
ring implantation; CT planning essential with \\
debridement of calcium that can potentially migrate \\
\end{tabular}

$C P B$, Cardiopulmonary bypass; $T V r$, tricuspid valve repair; $A V R$, aortic valve repair; $L V O T$, left ventricular outflow tract obstruction; $C T$, computed tomography. 
TABLE 4. Hospital outcomes of patients undergoing transcatheter mitral valve implantation in mitral annular calcification

\begin{tabular}{lccccc}
\hline $\begin{array}{c}\text { Patient } \\
\text { No. }\end{array}$ & $\begin{array}{c}\text { Postoperative } \\
\text { RRT }\end{array}$ & $\begin{array}{c}\text { ICU } \\
\text { stay (d) }\end{array}$ & CVA & $\begin{array}{c}\text { Hospital } \\
\text { stay (d) }\end{array}$ & $\begin{array}{c}\text { 30-d } \\
\text { mortality }\end{array}$ \\
\hline 1 & Yes & 11 & No & 30 & No \\
\hline 2 & No & 2 & Yes & 13 & No \\
\hline 3 & No & 2 & No & 2 & Yes \\
\hline 4 & No & 1 & No & 30 & No \\
\hline 5 & Yes & 7 & No & 31 & No \\
\hline 6 & No & 7 & No & 29 & No \\
\hline 7 & No & 5 & No & 24 & No \\
\hline 8 & No & 2 & No & 40 & No \\
\hline
\end{tabular}

$R R T$, Renal replacement therapy; $I C U$, intensive care unit; $C V A$, cerebrovascular accident.

64 patients from 32 centers who underwent TMVI. Three access routes were used: transseptal, transapical, and transatrial. Periprocedural death occurred in $29.7 \%$. The success achieved with the transatrial approach was $88.9 \%$, whereas the technical success with the transapical and transseptal approach was $71.4 \%$ and $65.4 \%$, respectively. Thirty-day mortality was $20 \%$ with transatrial approach, $32.1 \%$ with transapical approach, and $30.7 \%$ with the transseptal approach. The 1-year mortality seen in the TMVI in MAC Global Registry, via the transatrial, transapical, and transseptal approach $\left(35 \%, 56.5 \%\right.$, and $62.5 \%$, respectively). ${ }^{9}$ Patients who were alive at 1 year had significant improvement in symptoms. The TMVI in MAC Global Registry also highlighted LVOT obstruction and technical success to be independent predictors of 1-year mortality. ${ }^{9,10}$

In the case series by Praz and colleagues, ${ }^{11} 26$ patients underwent transatrial TMVI, mean STS score was 9.4\% (mean Euroscore II was $8.9 \%$ ), mean age was 78 years, and $92 \%$ were women. The technical success was reported as $100 \%$. In hospital mortality was $19 \%$ with a mean length

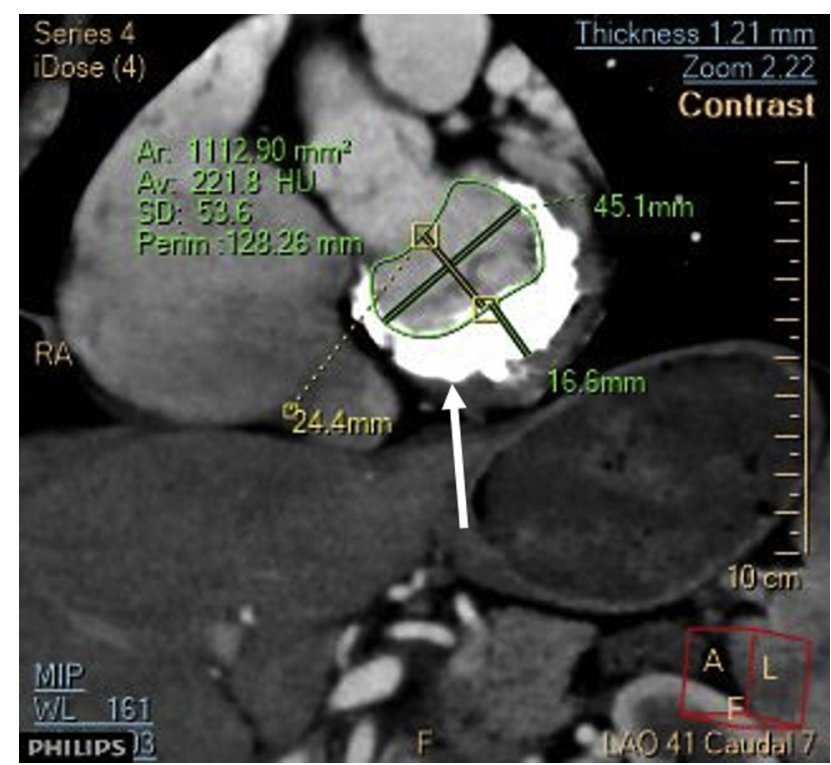

FIGURE 6. Computed tomography image showing horseshoe calcification of the mitral valve annulus (white arrow), maximum thickness $16.6 \mathrm{~mm}$. Mitral annulus dimensions $24.4 \times 45.1 \mathrm{~mm}$.

of stay of 13 days with a $38 \%$ PVL rate. At 8 months' follow-up there was a $34 \%$ mortality rate. ${ }^{1}$

Similarly, in the case series described by Russell and colleagues, ${ }^{12} 8$ patients underwent transatrial TMVI, mean STS score was $8 \%$, mean age was 61 years, and $50 \%$ were women. Procedural success at 30 days was $100 \%$. PVL immediately postimplantation was none or trace in 6 patients and mild in 1 patient. The mean length of stay was 7.9 days following surgery. There were no in-hospital or 30-day mortalities. No patient had a stroke. ${ }^{12}$

In our single-center experience of 8 patients with mitral valve pathology with severe MAC, the patients underwent transatrial TMVI performed by a single surgeon and by a

TABLE 5. Short-term outcomes of patients undergoing transcatheter mitral valve implantation in mitral annular calcification

\begin{tabular}{lccccc}
\hline Patient No. & $\begin{array}{c}\text { Postoperative NYHA } \\
\text { functional status at } \\
\text { 12-mo clinic follow-up }\end{array}$ & 1-y mortality & Current status & $\begin{array}{c}\text { Duration } \\
\text { of survival }\end{array}$ & Cause of death \\
\hline 1 & II & No & Dead & 24 mo & Right heart failure and end-stage renal failure \\
\hline 2 & II & No & Alive & $>12$ mo & - \\
\hline 3 & - & - & Dead & $2 \mathrm{~d}$ & Fixed cardiac output due to advanced \\
rheumatic disease; LVOT obstruction, \\
multiorgan failure
\end{tabular}

NYHA, New York Heart Association; LVOT, left ventricular outflow tract. *Preoperative pulmonary arterial pressure $105 \mathrm{~mm}$ Hg. 


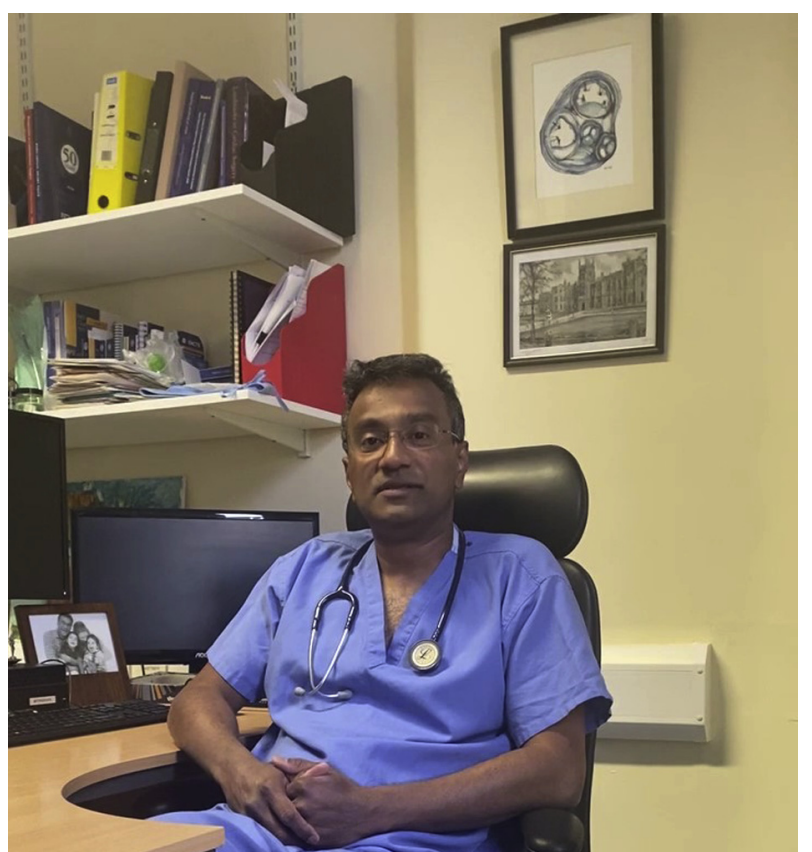

VIDEO 1. Summary of transcatheter mitral valve implantation procedure and outcomes. Video available at: https://www.jtcvs.org/article/S26662507(21)00552-6/fulltext.

cardiologist. In addition, 6 of the 8 patients had other concomitant procedures. We identified 4 technical considerations that must be addressed when performing TMVI in patients with underlying MAC (Video 1).

- PVLs and migration of prosthesis: This can occur in all cases and is easily resolved by stitching the atrial tissue onto the skirt of the transcatheter valve prosthesis (Figure 3$)^{13}$ and if necessary by securing a polytetrafluoroethylene strip on the skirt of the prosthesis in a continuous fashion (see Figure 5).

- Annular-prosthesis mismatch: This occurs when there is significant dilatation of the native calcified annulus making implantation not possible following sizing with a transcatheter balloon. This can potentially be resolved by implanting a complete annuloplasty ring (size 30 or 32) above the native annulus, thereby creating a neoannulus for valve-in-ring implantation (Figure 4). ${ }^{13}$

- LVOT obstruction: This is due to the anterior mitral valve leaflet being displaced into the LVOT by the prosthesis. During transatrial access, this can be easily resolved by excising the anterior mitral valve leaflet (Figure 2) and positioning the prosthesis away from the LVOT while ensuring the prosthesis is deployed in a supra-annular plane. This also allows for the skirt of the prosthesis to be secured to the atrial wall.

- MAC extending into myocardium with a calcific spur: CT planning is essential, allowing for debridement of cal- cium that can potentially migrate during balloon expansion and result in LV perforation.

The 30-day and 1-year mortality was $12 \%$ and $25 \%$, respectively. Similarly, as highlighted in the Registry, symptomatic improvement was seen in all these patients who were reviewed at outpatient follow-up except for 1 patient who developed pulmonary embolism. Apart from a prolonged hospital stay, postoperative complications encountered in this case series include 2 patients requiring temporary renal replacement therapy and 1 patient who experienced a stroke who was recovered at the time of the clinic review.

It is pertinent to mention the outcome of patients with MAC who did not undergo surgery. Niikura and colleagues ${ }^{14}$ looked at a group of patients who did not qualify for TMVI due to frailty and comorbidities. Seventy-six ineligible patients were treated with medical therapy. Their mean STS score was 9.4\%. He highlighted the 1-year mortality of these patients was $14.5 \%$ and rehospitalization due to heart failure was $22 \%$. It is important to mention that the patients treated with medical therapy had less mitral regurgitation (ie, volume of $65 \mathrm{~mL}$ vs $82 \mathrm{~mL}$ ) than those who were treated with TMVI or surgery. Fifty-six percent had NYHA functional class III or IV symptoms with a mean right ventricular systolic pressure of $40 \mathrm{~mm} \mathrm{Hg}{ }^{14}$ Twenty-four percent had moderate or severe MAC. Similarly, in our case series the 3 patients who were managed conservatively were alive at 12 months but all symptomatic with NYHA functional class III or IV symptoms. .

Outcomes from transatrial TMVI in MAC at 1 year seems to be improving in line with better patient selection by the heart team and stringent preoperative procedural planning to ensure technical success. But it cannot be denied that the mortality is still reasonably high, for both 30-day and 1-year outcomes, irrespective of access type for TMVI in $\mathrm{MAC}$, and therefore continued participation in large registries will better inform us with regard to patient selection and preoperative imaging indices for LVOT obstruction and other complications. However, patients who survive the initial postoperative period following surgery have a marked symptomatic improvement.

\section{Limitations}

This is a highly selected group of patients with multiple comorbidities who have undergone this procedure on the assumption that TMVI will have reduced complications in comparison to undergoing a conventional MVR procedure. There is a lack of randomized data comparing conventional MVR with transatrial TMVI. There are also few data comparing patients who underwent TMVI with those managed conservatively. Similarly, long-term outcomes following surgery are currently not known; however, further studies will inform this in the future. 


\section{CONCLUSIONS}

Technical success for selected patients undergoing TMVI for MAC can be significantly improved during open heart surgery by following simple but reproducible steps to prevent PVL, valve migration, and LVOT obstruction with favorable short-term outcomes. Early outcomes are dependent on postoperative LVOT obstruction and patient-related comorbidities. Because there are limited data worldwide, participating in registries and trials will better inform us of the role of TMVI in MAC.

\section{Conflict of Interest Statement}

This research included off-label use of the Sapien 3 (Edwards Life Sciences, Irvine, Calif) transcatheter valve in mitral position. Drs Spence and Jeganathan have received honoraria from Edward Lifesciences for consultancy work. All other authors reported no conflicts of interest.

The Journal policy requires editors and reviewers to disclose conflicts of interest and to decline handling or reviewing manuscripts for which they may have a conflict of interest. The editors and reviewers of this article have no conflicts of interest.

\section{References}

1. Eleid MF, Foley TA, Said SM, Pislaru SV, Rihal CS. Severe mitral annular calcification: multimodality imaging for therapeutic strategies and interventions. JACC Cardiovasc Imaging. 2016;9:1318-37.

2. Azariades M, Lennox SC. Rupture of the posterior wall of the left ventricle after mitral valve replacement: etiological and technical considerations. Ann Thorac Surg. 1988;46:491-4.

3. Casarotto D, Bortolotti U, Thiene G, Gallucci V, Cevese PG. [Rupture of the posterior wall of the left ventricle after replacement of the mitral valve: a description of 8 cases. G Ital Cardiol. 1977;7:387-94 [in Italian].
4. Kim SW, Jeong DS, Sung K, Kim WS, Lee YT, Park PW. Surgical outcomes of mitral valve replacement with concomitant mitral annular reconstruction. J Card Surg. 2018;33:69-75.

5. Hasan R, Mahadevan VS, Schneider H, Clarke B. First in human transapical implantation of an inverted transcatheter aortic valve prosthesis to treat native mitral valve stenosis. Circulation. 2013;128:e74-6.

6. Guerrero M, Dvir D, Himbert D, Urena M, Eleid M, Wang DD, et al. Transcatheter mitral valve replacement in native mitral valve disease with severe mitral annular calcification: results from the first multicenter global registry. JACC Cardiovasc Interv. 2016;9:1361-71.

7. Silbiger JJ. Anatomy, mechanics, and pathophysiology of the mitral annulus. Am Heart J. 2012;164:163-76.

8. Said SM, Schaff HV. An alternate approach to valve replacement in patients with mitral stenosis and severely calcified annulus. J Thorac Cardiovasc Surg. 2014; 147:e76-8.

9. Guerrero M, Urena M, Himbert D, Wang DD, Eleid M, Kodali S, et al. 1-Year outcomes of transcatheter mitral valve replacement in patients with severe mitral annular calcification. J Am Coll Cardiol. 2018;71:1841-53.

10. Guerrero M, Vemulapalli S, Xiang Q, Wang DD, Eleid M, Cabalka AK, et al Thirty-day outcomes of transcatheter mitral valve replacement for degenerated mitral bioprostheses (valve-in-valve), failed surgical rings (valve-in-ring), and native valve with severe mitral annular calcification (valve-in-mitral annular calcification) in the United States: data from the Society of Thoracic Surgeons/ American College of Cardiology/Transcatheter Valve Therapy Registry. Circ Cardiovasc Interv. 2020;13:e08425.

11. Praz F, Khalique OK, Lee R, Veeragandham R, Russell H, Guerrero M, et al Transatrial implantation of a transcatheter heart valve for severe mitral annular calcification. J Thorac Cardiovasc Surg. 2018;156:132-42.

12. Russell HM, Guerrero ME, Salinger MH, Manzuk MA, Pursnani AK, Wang D, et al. Open atrial transcatheter mitral valve replacement in patients with mitral annular calcification. J Am Coll Cardiol. 2018;72:1437-48.

13. Jeganathan R, Imran Hamid U, Johnston N, Owens C, Spence M, Manoharan G, et al. The role of surgical transcatheter valve implantation for the treatment of severe mitral annular calcification. J Card Surg. 2019;34:161-6.

14. Niikura H, Gossl M, Kshettry V, Olson S, Sun B, Askew J, et al. Causes and clinical outcomes of patients who are ineligible for transcatheter mitral valve replacement. JACC Cardiovasc Interv. 2019;12:196-204.

Key Words: mitral annular calcification, transcatheter mitral valve implantation, mitral valve disease 